\title{
Punching Shear Resistance of Slab with Shear Reinforcement According to Armenian and Foreign Building Standards
}

\author{
Hovhannes AVAGYAN
}

\begin{abstract}
The paper presents the results of punching shear values with reinforcement based on calculations of two and four storey cast-in-place reinforced concrete flat plate system buildings with spans of $4 \mathrm{~m}$ and $7 \mathrm{~m}$ by LIRA, Design Expert and RCM ACl-builder software in accordance with Armenian, Russian, European and American building standards under earthquake loading. In contrast to Eurocode 2 (EN 2) and American Concrete Institute (ACl), the building codes of the Republic of Armenia (SNiP) do not include the influence of bending moment in shear stress equation. The effect of punching shear on both interior and edge columns was carried out. To analyze the systems finite element method (FEM) was used. The results of comparison analysis show that according to SNiP the shear stresses do not exceed the limit even without reinforcement, whereas by foreign standards the differences between peak shear stresses with reinforcement and permissible shear reinforcement are marginal.
\end{abstract}

Keywords: building standards; earthquake loading; finite element method (FEM); flat plate; shear reinforcement

\section{INTRODUCTION}

A flat-plate floor system is a two-way concrete slab supported directly on columns with reinforcement in two orthogonal directions (Fig. 1). This system, which is popular in residential buildings (hotels, apartments and restaurants), has the advantages of simple construction and formwork and a flat ceiling, the latter of which reduces ceiling finishing costs because the architectural finish can be applied directly to the underside of the slab. Shear stresses at edge columns and corner columns are particularly critical because relatively large unbalanced moments can occur at those locations [1]. There are several types of reinforcement to provide the shear strength, such as headed shear stud and stirrup reinforcement (Fig. 2).

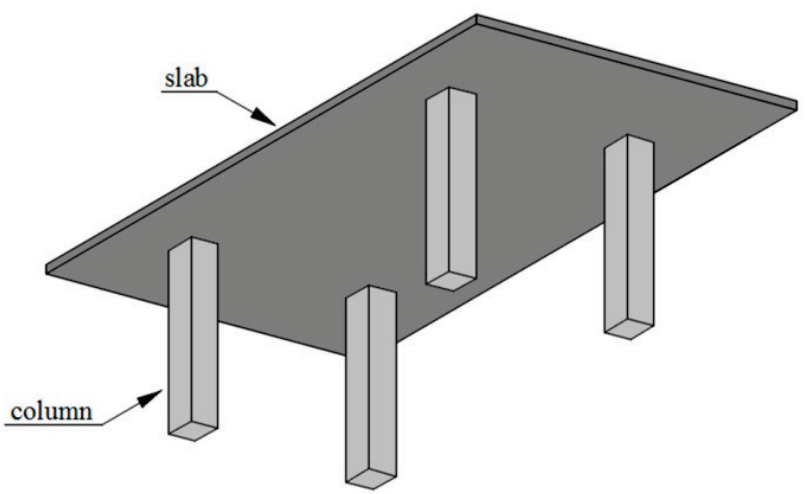

Figure 1 Schematic view of flat plate system

Buildings which are erected by flat plate systems became widespread in the Republic of Armenia, because of free planning and they are economically and ecologically profitable. Armenia is placed in a seismic region and the territory is divided in three seismic zones, where the accelerations of ground can be equal to $0,2 \mathrm{~g}$, $0,3 \mathrm{~g}$ and $0,4 \mathrm{~g}$ respectively [2]. Intersection of column and slab during the seismic action is risky because the bending moments can be notable. Consequently, the effect of earthquake loading is an important task for future calculations of flat plate systems. a)

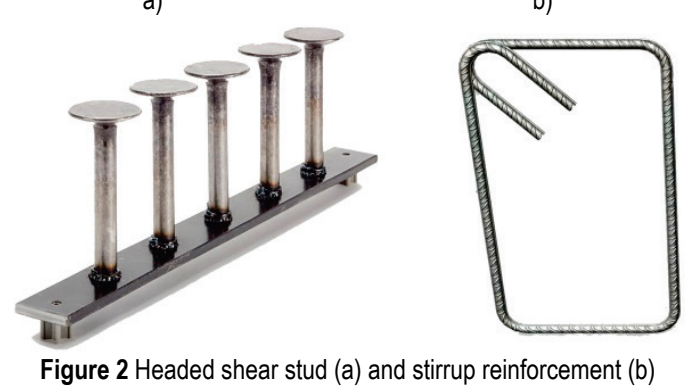

Last researches [3] have shown that the punching shear values according to $\mathrm{SNiP}$ [4] are satisfying the shear conditions without reinforcement, while in accordance with Russian standards (SP) [5] and EN 2 [6] these values are approximately 2,5 - 3,0 times larger than allowable, therefore it is necessary to put the additional steel bars for providing shear resistance. The main goal of the article is to obtain the shear stresses with reinforcement according to Armenian and foreign building codes, to check the general conditions of shear and to see how is affected the bending moment to punching shear observing various positions of columns, spans and storeys.

\section{INITIAL DATA OF TASK}

The cast-in-place reinforced concrete flat plate system buildings are investigated in the paper. The buildings have two and four storeys with spans of $4 \mathrm{~m}$ and $7 \mathrm{~m}$. Each storey height is equal to $3,0 \mathrm{~m}$. The strength class of concrete is C16/20 (B20) and the grade of steel bar is Grade 500 (A500C). In flat plate building the slabs have $22 \mathrm{~cm}$ thickness and the square columns have $50 \times 50 \mathrm{~cm}$ cross sections. All loads are assumed by the building standards. For comparison analysis not only SNiP, SP, EN 2 and ACI 318 [7] are included, but also the ground accelerations $0,2 \mathrm{~g}$ and $0,3 \mathrm{~g}$ for the first and second seismic zones respectively in accordance with [2]. Also the analyses of interior and edge columns are involved which are shown in Fig. 3. 


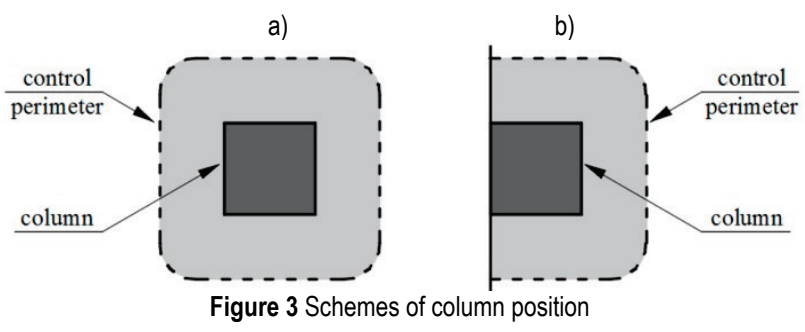

\section{PUNCHING SHEAR DESIGN OF SLABS WITH SHEAR} REINFORCEMENT

As shear reinforcement for current computations stirrups were chosen. All calculations by LIRA, Design Expert and RCM ACI-builder software were performed.

A slight difference in the forces is largely due to the difference of reliability and load combination factors.

The calculations under punching shear are performed for flat reinforced concrete members (slabs), when the concentrated forces and the bending moments are existing (Fig. 4).
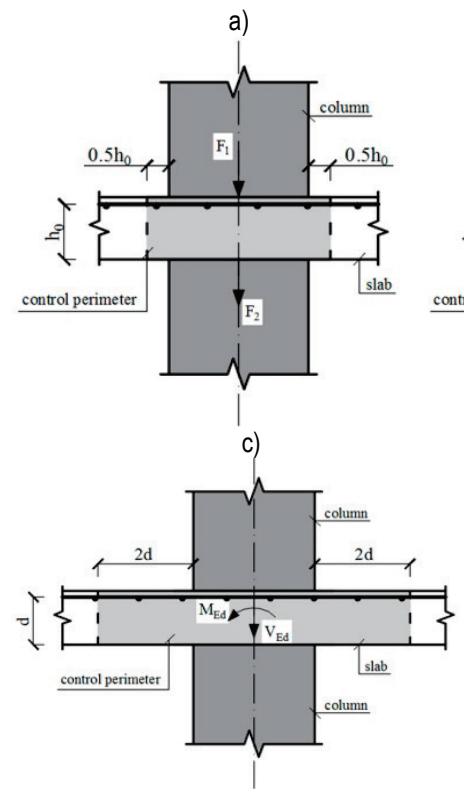

Figure 4 Design schemes of punching shear according to SNiP (a), SP (b), EN 2 (c) and $\mathrm{ACl} 318$ (d)

Design outline of transverse cross section is accepted locked and is placed around the area of the load transmission, when the platform of load transmission is located inside the flat element.

In accordance with [4] the shear stresses with reinforcement are determined from the following condition:

$$
F \leq \alpha \cdot R_{b t} \cdot u_{m} \cdot h_{0}+0,8 \cdot F_{s w}
$$

As noted from Eq. (1) only axial force is included.

In accordance with [5] the bearing capacity of elements with transverse reinforcement under punching force taking into account the concentrated force and bending moments mutually of two perpendicular planes should satisfied:

$$
\begin{aligned}
& \frac{F}{F_{b, u l t}+F_{s w, u l t}}+\frac{M_{x}}{M_{b x, u l t}+M_{s w, x, u l t}} \\
& +\frac{M_{y}}{M_{b y, u l t}+M_{s w, y, u l t}} \leq 1
\end{aligned}
$$

According to [6] at the column perimeter, or the perimeter of the loaded area, the maximum punching shear stress with reinforcement shall not be exceeded:

$$
\frac{\beta \cdot V_{E d}}{u_{i} \cdot d} \leq 0,75 V_{R d, c}+1,5 \cdot \frac{d}{s_{r}} A_{s w} f_{y w d, e f} \cdot \frac{1}{u_{1} \cdot d} \cdot \sin \theta
$$

Shear strength with reinforcement according to [7] is based on

$$
\begin{aligned}
& \Phi\left(0,33 \lambda \sqrt{f_{c}^{\prime}}+\frac{A_{v} f_{y t} d}{s}\right) \geq \frac{V_{u}}{A_{c}}+\gamma_{v x} \cdot \frac{M_{u x}}{I_{x}} \cdot C_{2}+ \\
& +\gamma_{v y} \cdot \frac{M_{u y}}{I_{y}} \cdot C_{1}
\end{aligned}
$$

In the conditions (1), (2), (3) and (4) the coefficients and parameters are the following:

$F, V_{E d}$ and $V_{u}$ are design values of the applied shear force by [4-7] respectively, $\mathrm{N}$

$R_{b t}$ and $f_{c}^{\prime}$ are compressive strengths of concrete, $\mathrm{MPa}$

$M_{x}$ and $M_{y}, M_{u x}$ and $M_{u y}$ are factored bending moments in $\mathrm{X}$ and $\mathrm{Y}$ directions from external load, $\mathrm{N} \cdot \mathrm{mm}$

$F_{b, u l t}, M_{b x, u l t}, M_{b y, u l t}$ are ultimate force and accordingly the bending moments in $X$ and $Y$ directions which can be perceived by concrete, $\mathrm{N}, \mathrm{N} \cdot \mathrm{mm}$

$F_{s w, u l t}, M_{s w, x, u l t}, M_{s w, y, u l t}$ are ultimate force and accordingly the bending moments in $X$ and $Y$ directions which can be perceived by stirrup.

$\beta$ is a coefficient, it depends on the position of column and internal bending moment, calculated by [6],

$u_{m}$ and $u_{i}$ are control perimeters of concrete cross section, $\mathrm{mm}$

$h_{0}$ and $d$ are effective depths in the orthogonal directions, $\mathrm{mm}$

$\alpha$ and $\lambda$ are the modification factors depending on mechanical properties of concrete, for heavy weight concrete $\alpha=1,0$ and for normal weight concrete $\lambda=1,0$, $V_{R d, c}$ is a design value of the shear resistance without shear reinforcement, $\mathrm{N}$

$s$ and $s_{r}$ are the radial spacing of the stirrups, $\mathrm{mm}$ $A_{s w}$ and $A_{v}$ are the cross-sectional areas of shear reinforcement, $\mathrm{mm}^{2}$

$\theta$ is the angle between the shear reinforcement and the plane of the slab,

$\Phi$ is the strength reduction factor, for shear it equals $\Phi=$ 0,75 ,

$A_{c}$ is the area of concrete of assumed critical section, $\mathrm{mm}^{2}$ $\gamma_{v x}$ and $\gamma_{v y}$ are factors, and shall be considered to be transferred by eccentricity of shear about the centroid of the critical section,

$I_{x}$ and $I_{y}$ are the moments of inertia over $X$ and $Y$ axes respectively, $\mathrm{mm}^{4}$

$C_{1}$ and $C_{2}$ the half sides which are perpendicular to vertical axis of column, $\mathrm{mm}$ 
According to (1) and (2) shear stresses respectively will be equal to

$$
\begin{aligned}
& \tau_{1}=\frac{F}{u_{m} \cdot h_{0}} \\
& \tau_{2}=\frac{F}{u \cdot h_{0}}+\frac{M_{x}}{2 W_{b x} \cdot h_{0}}+\frac{M_{y}}{2 W_{b y} \cdot h_{0}}
\end{aligned}
$$

Depending on many factors like strength class of concrete, grade of steel bar, radial spacing of steel bar and control perimeter the shear reinforcement $\left(\nu_{R d, c s}\right)$ according to [4] is equal to $1,20 \mathrm{MPa}$, by [5] is $0,352 \mathrm{MPa}$, in case of [6] is equal to $1,526 \mathrm{MPa}$ and in accordance with [7] the nominal shear strengths with reinforcement for interior and edge columns are 1,174 MPa and 1,208 MPa relatively.

The external forces gathered from $\mathrm{FE}$ analysis for each position of column, span and building code are shown in

\begin{tabular}{|c|c|c|c|c|c|}
\hline \multirow{2}{*}{$\begin{array}{l}.00 \\
.0 \\
0 \\
0 \\
0 \\
0 \\
0 \\
0\end{array}$} & \multirow{2}{*}{$\begin{array}{l}\Xi \\
\equiv \\
\text { हี } \\
\text { के }\end{array}$} & \multirow{2}{*}{ 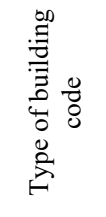 } & \multirow{2}{*}{$\begin{array}{c}\text { Design } \\
\text { shear force } \\
V_{E d} \times 10^{6} / \mathrm{N}\end{array}$} & \multicolumn{2}{|c|}{$\begin{array}{l}\text { Internal bending moment / } \\
\qquad \mathrm{N} \cdot \mathrm{mm}\end{array}$} \\
\hline & & & & $M_{E d, x} \times 10^{6}$ & $M_{E d, y} \times 10^{6}$ \\
\hline \multirow{8}{*}{ 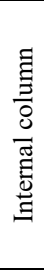 } & \multirow{4}{*}{4} & SNiP & 161,7 & - & - \\
\hline & & SP & 161,7 & 15,08 & 144,04 \\
\hline & & EN 2 & 139,4 & 35,4 & 326,5 \\
\hline & & ACI 318 & 179,8 & 226,2 & 234,2 \\
\hline & \multirow{4}{*}{7} & SNiP & 510,0 & - & - \\
\hline & & SP & 510,0 & 27,66 & 167,58 \\
\hline & & EN 2 & 439,4 & 40,3 & 359,9 \\
\hline & & ACI 318 & 566,7 & 192,7 & 263,0 \\
\hline \multirow{8}{*}{ 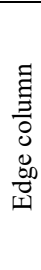 } & \multirow{4}{*}{4} & SNiP & 283,6 & - & - \\
\hline & & $\mathrm{SP}$ & 283,6 & 10,98 & 100,92 \\
\hline & & EN 2 & 177,0 & 24,7 & 218,7 \\
\hline & & ACI 318 & 183,3 & 175,7 & 164,3 \\
\hline & \multirow{4}{*}{7} & SNiP & 318,2 & - & - \\
\hline & & $\mathrm{SP}$ & 318,2 & 18,93 & 183,23 \\
\hline & & EN 2 & 297,5 & 27,7 & 357,9 \\
\hline & & ACI 318 & 368,1 & 342,4 & 184,7 \\
\hline
\end{tabular}
Tab. 1 .
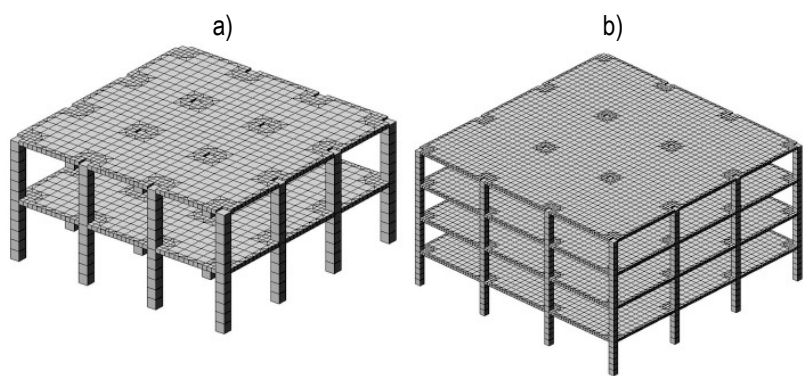

Figure $5 \mathrm{FE}$ models for simulation analysis, two storeys flat plate building with 4 $\mathrm{m}$ spans (a), four storeys flat plate building with $7 \mathrm{~m}$ spans $(\mathrm{b})$

As mentioned above the main calculations by LIRA software were carried out. By Design Expert the shear reinforcement was checked for EN 2 and by RCM ACIbuilder for ACI 318.

A more detailed meshing process for column-slab intersections was done (Fig. 5).

\section{RESULTS OF FE ANALYSIS}

Final results of maximum shear stresses depending on accelerations, column positions, length of spans, storey and building codes are shown in Tab. 2.

\begin{tabular}{|c|c|c|c|c|c|c|c|}
\hline \multirow{2}{*}{$\frac{\tilde{0}}{\stackrel{0}{0}}$} & \multirow{2}{*}{$\begin{array}{l}\text { : } \\
: \\
0 \\
0 \\
0 \\
0 \\
\Xi \\
0 \\
0 \\
0\end{array}$} & \multirow{2}{*}{ 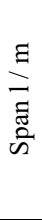 } & \multirow{2}{*}{ 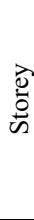 } & \multicolumn{4}{|c|}{ Maximum shear stresses / $\mathrm{MPa}$} \\
\hline & & & & $\tau_{1}$ & $\tau 2$ & $v_{E d}$ & $v_{u}$ \\
\hline \multirow{8}{*}{$\begin{array}{l}\stackrel{0}{1} \\
\text { ֻे }\end{array}$} & \multirow{4}{*}{ 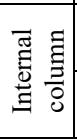 } & \multirow{2}{*}{4} & 1 & 0.310 & 0.094 & 0.362 & 0.342 \\
\hline & & & 2 & 0.270 & 0.074 & 0.283 & 0.313 \\
\hline & & \multirow{2}{*}{7} & 1 & 0.960 & 0.261 & 0.854 & 1.073 \\
\hline & & & 2 & 0.850 & 0.219 & 0.702 & 0.953 \\
\hline & \multirow{4}{*}{ 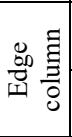 } & \multirow{2}{*}{4} & 1 & 0.220 & 0.078 & 0.297 & 0.257 \\
\hline & & & 2 & 0.140 & 0.051 & 0.188 & 0.162 \\
\hline & & \multirow{2}{*}{7} & 1 & 0.600 & 0.229 & 0.784 & 0.684 \\
\hline & & & 2 & 0.400 & 0.161 & 0.550 & 0.453 \\
\hline \multirow{16}{*}{$\stackrel{\infty}{\infty}$} & \multirow{8}{*}{ 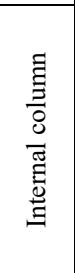 } & \multirow{4}{*}{4} & 1 & 0.310 & 0.184 & 0.719 & 0.350 \\
\hline & & & 2 & 0.300 & 0.184 & 0.723 & 0.344 \\
\hline & & & 3 & 0.290 & 0.145 & 0.550 & 0.322 \\
\hline & & & 4 & 0.260 & 0.090 & 0.320 & 0.298 \\
\hline & & \multirow{4}{*}{7} & 1 & 0.970 & 0.338 & 1.142 & 1.098 \\
\hline & & & 2 & 0.960 & 0.345 & 1.170 & 1.090 \\
\hline & & & 3 & 0.950 & 0.304 & 1.002 & 1.051 \\
\hline & & & 4 & 0.850 & 0.231 & 0.723 & 0.946 \\
\hline & \multirow{8}{*}{ 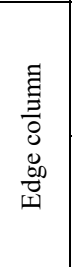 } & \multirow{4}{*}{4} & 1 & 0.540 & 0.191 & 0.584 & 0.359 \\
\hline & & & 2 & 0.280 & 0.142 & 0.552 & 0.292 \\
\hline & & & 3 & 0.290 & 0.122 & 0.458 & 0.206 \\
\hline & & & 4 & 0.160 & 0.066 & 0.241 & 0.182 \\
\hline & & \multirow{4}{*}{7} & 1 & 0.610 & 0.274 & 0.963 & 0.719 \\
\hline & & & 2 & 0.470 & 0.256 & 0.905 & 0.563 \\
\hline & & & 3 & 0.610 & 0.265 & 0.901 & 0.501 \\
\hline & & & 4 & 0.410 & 0.173 & 0.573 & 0.456 \\
\hline
\end{tabular}

Table 2 Results of shear stresses

The variations of shear stresses depending on storey and distances of spans in graphics are described in Fig. 6. All graphics by Wolfram Mathematica were implemented.

The variations of shear stresses in case of seven meters and interior column according to all four building codes [4 $\div 7]$ are shown in Fig. 7 .

\section{CONCLUSION}

Comparing last research [3] with current one it is obvious that the limited shear stress according to [4] increases about 1,33 times and as well as [6] grows 3.30 times. Consequently, in accordance with $[4,6]$ including seismic force for these types of buildings the shear reinforcement is necessary.

To sum up, the punching shear resistances apart from interior column of four storey building with seven meters spans are satisfying the shear strength condition even without reinforcement according to [4]. When is considered [5] the difference between shear reinforcement and maximum shear stress is approximately $4 \%$. Furthermore, in accordance with [6] and [7] these differences are $34 \%$ and $7 \%$. It means that the peak shear stresses with reinforcement and permissible shear reinforcement are very close values.

After all, in shear stress condition the interior bending moment has a significant role, especially when the structure is located in the seismic region. 
a)

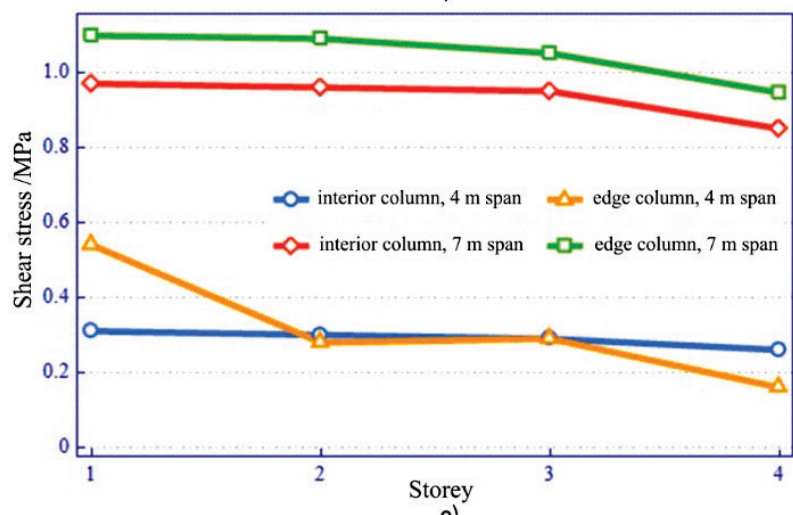

c)

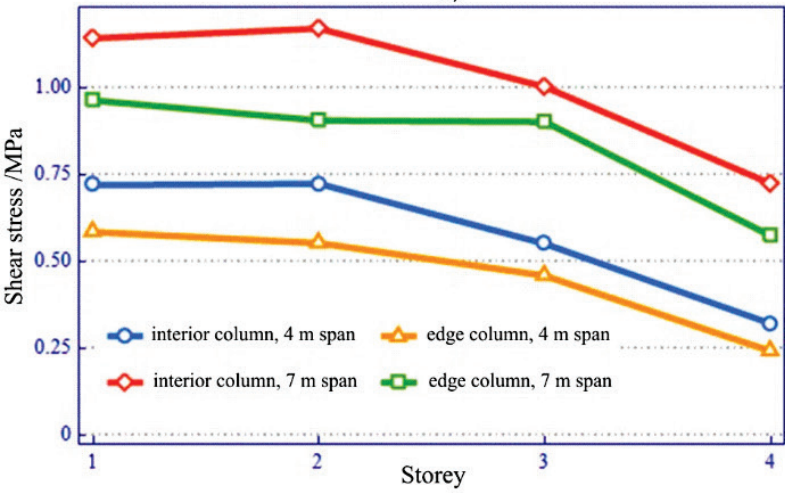

Figure 6 Relationships of shear stresses with reinforcement on number of storeys, spans, and column positions according to [4] $-a,[5]-b,[6]-c$ and [7] - $d$
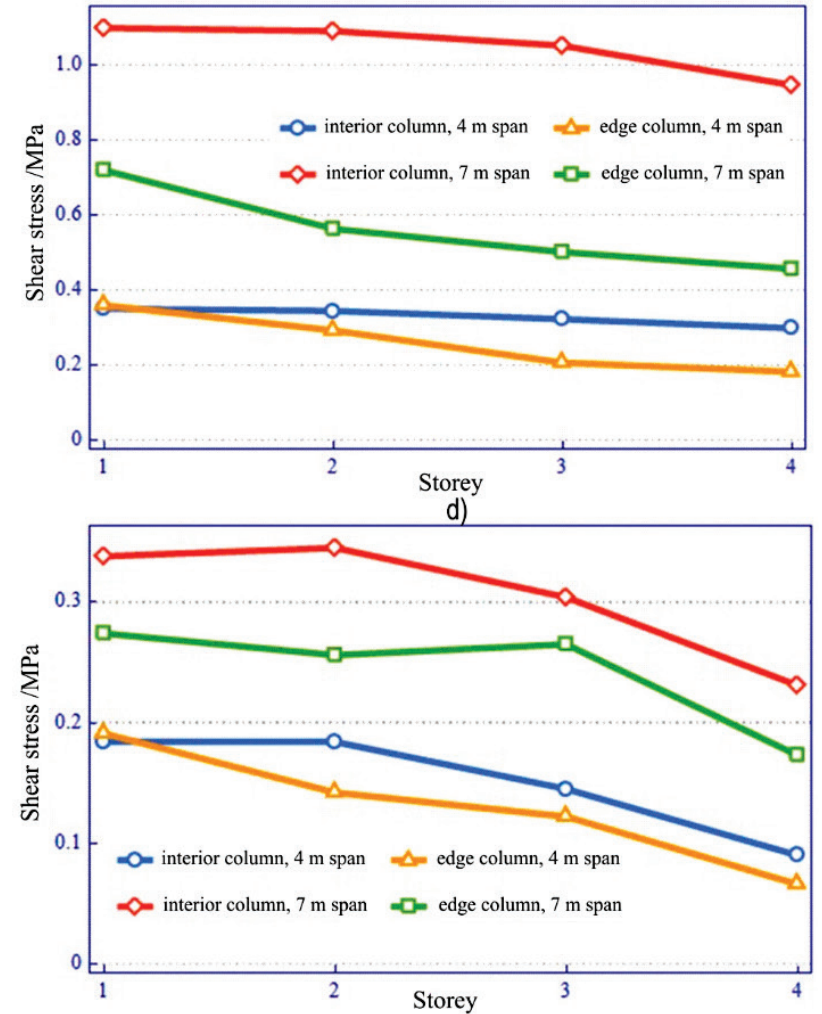

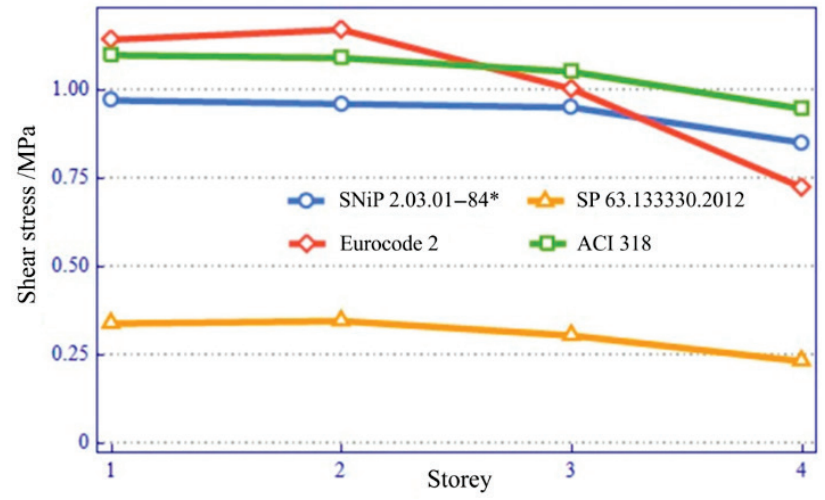

Figure 7 Relationships of shear stresses with reinforcement on number of storeys according to $[4 \div 7]$

\section{REFERENCES}

[1] David, A. F. (2016). Reinforced Concrete Structures: Analysis and Design, $2^{\text {nd }}$ Edition. McGraw-Hill Education, Washington.

[2] RABC II-6.02-2006: Building Code, Earthquake Resistant Construction Design Codes.

[3] Dadayan, T. \& Avagyan, H. (2016). The Comparison Analysis of Punching Shear Resistance of Flat Plate Systems According to Various Building Codes. International Conference on Contemporary Problems of Architecture and Construction, Proceedings of $8^{\text {th }}$ Int. Conference / Armenia, 69-72.

[4] SNiP 2.03.01-84*. (1989). Concrete and Reinforced Concrete Structures.

[5] SP 63.133330.2012. (2012). Concrete and Reinforced Concrete Structures. Basic Provisions. Updated Edition of SNiP 52-01-2003.

[6] Eurocode 2. (2004). Design of concrete structures.

[7] ACI 318M-08. (2008). Building Code Requirements for Structural Concrete (ACI 318M-08) and Commentary. 